臨床耳鼻：第3卷・第2號・1992

Clin. Otol. pp 323 328

Vol. 3, No. 2, 1992

$$
\text { 하악 골절의 구강내 관혈적 정복술 }
$$

한일병원 이비인후과, 성형외과*

전성호 · 최득록 · 백승대 · 김종곤 · 김창원 - 이해욱*

\title{
Intra-oral Open Reduction of Mandibular Fractures
}

\author{
Seong Ho Chun, M.D., Deuk Rok Choi, M.D., Seung Dae Baek, M.D., \\ Jong Gon Kim, M.D., Chang Won Kim, M.D., Hae Wook Lee, M.D.* \\ Department of Otolaryngology and Maxillofacial Surgery, Plastic \& Reconstructive Surgery,* \\ Hanil General Hospital
}

\section{$=$ Abstract $=$}

Many treatment methods for mandibular fractures have already been used. Among them, open reduction and internal fixation is widely utilized to provide more accurate reduction and secure fixation for selected cases. The traditional approach to this procedure has been through a skin incision concealed in the submandibular or submental shadow. This extraoral approach allows the clean dissection and interosseous wiring or plating to be separated from the orally contaminated dental wiring and extraction. However, some problems such as external scar, the possibility of facial nerve injury and the failure or incomplete result of immobilization have been indicated. Open reduction performed through an oral mucosal incision was first described by Kazanjian in 1933. This technique provided adequate fixation without external scar and facial nerve injury. The purpose of this report is to present our cases and to provide a review of the technique that will be useful to surgeon.

KEY WORDS: Mandibular fractures - Intra-oral open reduction.

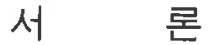

하악 골절은 악안면 골절중 비골 골절 다음 으로 많은 빈도를 보이며, 치료에 있어서도 여 러가지 다양한 방법들이 사용되고 있다. Hippocrates의 턱 붕대 및 금 철선과 실을 사용한 방법에서부터 Thomas Brian Gunning의 부목, Gilmer의 악간 고정법, Kinlock의 관혈적 정복 및 강선 내고정을 거쳐 최근의 miniplate, 압박 금속판(dynamic compression plate, DCP), 유 도나사(lag screw)에 이르기까지 여러가지 방 법이 이용되었다.5). 그러나 모든 치료의 목표는 교합의 회복이라 하겠다. 하악 골절 치료의 여 러 방법중에서 저자들은 최근에 경험한 구강내 정복술에 대하여 검토하였다.

\section{연구대상 및 방법}

1988년 10월부터 1991년 4월까지 1년 6개월 
간 하악 골절로 한일병원 이비인후과에서 치 료받은 환자 20 명과 성형외과에서 치료받은 8 명의 환자에서 발생한 41 례의 골절줍 구강내 정복술을 시행받은 17 례를 대상으로 하였으며, 연령분포, 부위별 분포, 수술방법 및 결과에 대하여 관찰하였다.

연령별로는 10 대에서 60 대에 분포되어 있었 으며, 대부분 남자였다(Table 1). 부위별로는 주로 정중부와 체부이었으며, 우각부 2 례, 근 돌기 1례였다(Table 2). 내고정의 방법으로는 16례중 14례에서 monocortical miniplate가 사 용되었고, 2례에서 강선이 사용되었다. Miniplate가 사용된 예의 골절당 miniplate의 사용 갯수는 1.6 개였다(Table 3).

\section{수 술 방 법}

전례에서 술전 betadine희석액을 사용하여 충분한 구강 세척을 시킨 후, 비기관 튜브를 통한 전신 마취하에서 앙와위로 상체를 약간 올린 상태에서 수술하였다.

정중부의 경우, 양측 견치사이에 labiobuccal vestibular incision으로 절개후 골막까지 박리 하였다.

근정중부에서는 절개를 제 2 대구치까지 연장 하였고, 이신경 (mental nerve)을 유리시켜 시 야를 확보하였다. 골절편이 노출된 상태에서 골겸자 둥을 이용하여 정복하고, 타월 클램프 등을 사용하여 골절편의 배열을 맞춘 상태에서 hand drill로 burr hole을 뜷고 miniplate로 고 정하였다. Miniplate는 골절부위의 면에 정확 히 맞게 bending plier로 구부려 사용하고, 정 중부에서는 염전력을 견딜 수 있게 2 개를 사 용하였다. 이때 각 plate는 적어도 $5 \mathrm{~mm}$ 이상 떨어지도록 하며, 서로 평행하게 하였다. Screw는 대개 길이 $7 \mathrm{~mm}$ 내지 $9 \mathrm{~mm}$, 직경 $2 \mathrm{~mm}$ 를 사용하였다. Plating후 생리식염수로 충분히 세 척한 후 4-0 chromic으로 골막과 점막을 봉합 하였다. 체부에서는 88 년에 수술한 2 례는 강선 을 사용하였으나, 그 이후는 모두 plate를 사용 하였다. 정중부의 8 례중 1 례에서는 $\operatorname{arch}$ bar나
Table 1. Age and sex distribution

\begin{tabular}{cccc}
\hline Age & Male & Female & Total \\
\hline $11 \sim 20$ & 2 & & 2 \\
$21 \sim 30$ & 5 & 1 & 6 \\
$31 \sim 40$ & 4 & & 4 \\
$41 \sim 50$ & 3 & & 3 \\
$51 \sim 60$ & 1 & & 1 \\
$61 \sim 70$ & 1 & & 1 \\
\hline Total & 16 & 1 & 17 \\
\hline
\end{tabular}

Table 2. Sites of mandibular fracture

\begin{tabular}{lc}
\hline \multicolumn{1}{c}{ Sites } & Cases $(\%)$ \\
\hline Symphysis & $8(47)$ \\
Body & $6(35)$ \\
Angle & $2(12)$ \\
Coronoid & $1(6)$ \\
\hline Total & $17(100)$ \\
\hline
\end{tabular}

Table 3. Methods of fixation

\begin{tabular}{ccc}
\hline Miniplate & Wire & Total \\
\hline 14 & 2 & 16 \\
\hline
\end{tabular}

* No. of miniplate per fractures : 1.6

악간고정을 하지 않았고, 1 례는 tension band 로 arch bar를 사용하였으며, 6 례에서는 3 일에 서 21 일간의 악간고정을 하였다. 타병원에서 관혈적 정복술 및 강선 내고정 후 가관절증을 보였던 1 례에서는 재수술을 시행하여 miniplate로 고정후 35 일간 악간 고정을 시행하였다. 우각부의 경우는 제3 대구치 뒤쪽 하악지 전연의 중간에서부터 제 1 대구치까지 sagittal split osteotomy incision으로 절개 후, 골막을 박리하여 골절부위를 노출시켰다. 골겸자 둥을 사용하여 정복 후 정렬시켜 miniplate를 사용 하여 고정하였다. 1례에서는 4-hole miniplate 1 개로 external oblique ridge를 따라 고정하였 으며, 1례는 4-hole miniplate 2개로 external oblique ridge와 superior buccal cortical area 에 고정하였는데, 이때는 stab incision과 guide를 사용하는 방법이 필요하였다. 악간고 정은 각각 14 일, 20 일간 시행하였다.

근돌기부의 골절은 1 례가 있었으며 점막절 
개를 통하여 골절편을 제거하였다.

\section{결 과}

골절편을 제거했던 근돌기부 1 례를 제외한 전체 16 례에서 평균 악간고정 기간은 miniplate를 사용한 경우 13.6 일, 강선고정의 경우 35 일이었다.

합병증으로 체부골절 1례에서 miniplate 고 정 후 4 일에 염증이 발생하였으나 절개부위로 세척 및 배농후 치유되었으며 그외는 별다른 문제점이 없었으며, 6 개월 후의 추적 방사선 검사에서도 이상소견은 보이지 않았다.

\section{고 찰}

하악 골절은 악안면 외상 환자의 $45.5 \%$ 를 차지하고 있으며, 협꼴 손상을 가장 잘 동반하 는 것으로 알려져 있다9). 또한, 반수 이상에서 다발성 골절을 보이므로 치료시 언제나 제2 골절의 가능성을 염두에 두어야 한다(예를 들 면, 정중부와 반대편 과두경부, 우각부와 반대 편 체부 둥) ${ }^{10)}$,

하악 골절의 치료에서는 우선 과거 교합의 회복이 가장 중요하겠다3,14,16). 그 방법을 역사 적으로 살펴보면히, 하악 골절의 기록은 이집트 의 Papyrus에서 처음으로 나타나 있는데 이는 기원 전 3000 년경의 기록으로 보인다. 그후 Hippocrates는 chin bandage, gold wire와 linen thread를 사용하였고, 이후 Hippocrates의 방법 이 약간씩 변화되어 사용되었으며, 1275 년 Salicetti는 처음으로 악간 고정에 관하여 언급하 였고, 1795년 Chopart와 Desault의 device, 18 16 년 Barton의 Bandage의 순으로 발전되었다. 1800 년대에 들어와 Buck와 Kinlock이 관혈적 정복술 및 강선 내고정, Thomas가 은강선을 이용하여 구강내로 관혈적 정복을 시행하는 Thomas principle을 제시하였으며, Gilmer가 악간 고정을 처음 사용하였고, 또한 Gilmer는 1881 년 두개의 막대기를 골절부의 양쪽에 대고
강선으로 감아주었는데 이것이 bone plate의 시초로 보인다. 최근에는 miniplate, 역동압박 판(dynamic compression plate : DCP), 유도나 사(lag screw)가 주로 이용되는데 과거로부터 의 모든 방법들이 공통적으로 호과적인 고정에 의한 교합의 회복에 역점을 두었다고 하겠다.

하악 골절의 치유 과정은 ${ }^{11}$ 알려진 바와 같 이 골절부 주위에 혈종이 형성되어 염중성 반 응이 진행되면서 모세혈관의 내방성장과 더불 어 혈종이 육아조직으로 바뀌고, 이 육아조직 이 성숙되어 섬유조직을 거쳐 섬유연골이 만 들어진다. 여기에서 연골아세포가 연골세포로 되고 골강을 형성하며 이곳으로 골아세포가 들어가 골유기기질이 만들어지고 골이 형성되 는 과정이 secondary bone healing 또는 indirect bone healing이며, 골절 주위의 특징적인 방사선적 음영을 갖는 섬유연골과 골을 골막 가골(periosteal callus)이라 부른다. 이와같이 가골이 골절부 틈사이의 다리로써 내고정물로 작용하며 후에 remodeling과정을 거쳐 치유과 정이 완성된다. 이와는 대조적으로 결합조직의 내방성장이 없이 골절부의 양끝에서 Haversian canal의 증식으로 골절편이 서로 연결되 면서 active remodeling이 진행되는 과정을 primary bone healing 또는 direct bone healing이라 하는데, 이때는 반드시 강성고정(rigid fixation)이 필요하겠다. 이 과정에서는 파 골세포들이 치밀질 속으로 터널을 만들고(이 것을 cutter cone이라 함), 이 터널사이로 혈관 이 자라들어가며 골아세포에 의하여 새로운 골이 형성된다. 또한 하악골절에서 골절부의 양끝에서 혈관과 골아세포가 자라면서 골유기 기질이 쌓이면서 골단위가 만들어지는 과정을 gap healing이라 하는데, 역시 direct bone healing의 한 형태로 보인다. Luhr 등은 하악 에서의 모든 primary bone healing은 gap healing이라고 하였다.

하악골절의 치료목적은 무엇보다 기존 교합 의 회복에 중점을 두고 있으며, 그 방법으로는 첫째, 능동적 치료없이 관찰하는 경우 둘째, 악간고정만 하는 경우 셋째, 관혈적 정복 및 내고정하는 경우 넷째, Gunning type 부목 등 
장치를 사용하는 경우로 나눌 수 있으며, 저자 들의 예는 세번째에 해당한다. 관혈적 정복술 의 접근 방법도 크게 외부 접근방법과 구강내 접근방법으로 나눌 수 있는데, 저자들이 사용 한 구강내 접근방법은 1933년 Kazanjianㄲㅇㅣ 기 술한 바 있으며, 장점으로 외부 반흔이 없고, 수술시간이 짧고, 치아나 골절편의 제거가 용 이하다. 이와 더불어 non-compression miniplate를 사용한 경우, 강성고정이 가능하고, 악 간고정을 생략할 수 있으며, 정상적인 하악운 동의 조기회복이 가능하다 하겠다. Non-compression miniplate를 사용한 구강내 관혈적 정 복술의 단점으로는 특별한 기구와 술기가 필 요하고, 이신경의 손상 가능성이 있다. 저자들 은 구강내 접근법에 의한 우각부 골절의 치료 시 1 례에서는 miniplate 1 개를, 1 례에서는 2 개 를 사용하였다. Levy 둥 ${ }^{12)}$ 은 63 례의 우각부 골 절에서 non-compression monocortical miniplate를 사용하여 구강내 관혈적 정복술로 치료 하였으며, miniplate 1 개를 사용한 경우와 2 개 롤 사용한 경우로 나누어 비교하여 우각부에 서는 2 개의 miniplate를 사-용하는 것이 치료에 더욱 효과적이라 하였으며, 우각부에서 sagittal osteotomy incision을 통하여 miniplate를 사용 한 경우 외부 반흔이 없고, 안면신경의 하악연 지나 하치조신경의 손상이 없으며, 골절선과 교합의 관계를 한눈에 볼 수 있는 장점이 있 다고 하였다.

골절부의 치아의 처리에 있어서 과거에는 감염의 문제 등으로 제거하는 것이 좋다고 하 였으나, 저자들의 경우 가능한 한 보존하는 것 을 원칙으로 하였으며, Amaratunga 둥ㄹㅇㅢ 보 고에서도 치아를 제거한 경우와 안한 경우 합 병증의 유의한 차이를 보이지 않았다. 또한 Randa $1^{10)}$ 의 보고에서도 판정기준에 들지 않는 경우 보존하였으며, 발치의 판정기준으로서, 4 + 의 가동성, 치근골절, 치근첨의 병변이 있는 경우와 골절편이 고정에 방해되는 경우를 제 시하였다. 또한, Shetty와 Freymiller ${ }^{15)}$ 는 과거 의 논문을 검토하여 골절부 치아의 처리에는 많은 논란이 있으나, 그 지표로서 치아의 보존 을 결정하는 데는 치료시기가 한 요인으로 작
용되며, 치아가 골절의 정복을 방해하는 경우, 치주조직의 손상이 크면서 치조골절이 동반된 경우, 치근골절의 경우는 치아를 제거하는 것 이 좋으며, 치관골절이 있어도 응급 근관치료 가 가능하면 치아를 보존하고, 골절부의 정상 치아나 완전히 매몰된 대구치의 궁우도 특별한 문제가 없는 한 보존하며, 손상당시 회복불능 으로 보이는 경우라도 회복가능성이 남아 있 으므로 일단 보존적 요법으로 치료할 것을 주 장하였다.

하악 골절의 내고정의 방법 ${ }^{12)}$ 으로는 강선, miniplate, $\mathrm{DCP}$ 와 유도나사를 사용할 수 있으 며, 이중에서 miniplate, $\mathrm{DCP}$ 와 유도나사는 강 성고정이 가능하다. 각각의 특성을 살펴보면, $\mathrm{DCP}$ 의 경우 양쪽 피질에 나사가 작용하기 때 문에 완벽한 압박과 강성고정이 가능하다고 하였으나, Worthington 둥은 압박이 골형성을 촉진시킨다는 중거가 없으며, $\mathrm{DCP}$ 는 너무 단 단하기 때문에 stress shielding effect에 의하 여 도움이 되지 않으므로 monocortical miniplate의 사용을 주장하였다. 또한, 압박판을 주 장하는 사람들은 나사가 양쪽 피질에 작용하지 않고는 강성고정이 될 수 없다고 하였으나, Champy 등은 생체역학적 연구에서 비압박적 방법으로도 강성고정에 의한 치유가 가능하다 고 하였고, 톡히 하악의 모든 점에서 염전력, 장력, 압박을 견딜 수 있는 골접합의 ideal line을 제시하여, 이를 Champy's ideal line이라 하였다. Worthington과 Champy 둥은 생리적 긴장은 압전효과(piezoelectric effect)나 기계 화학적 효과(mechanochemical effect)에 의해 골형성 세포를 자극하며, 반대로 생리적 자극 이 적은 경우, 골의 손실을 초래하므로 plate가 너무 rigid하면 stress shielding effect를 가져 올 수 있다고 하였다. miniplate는 대개 60 $100 \mathrm{daN} / \mathrm{mm}^{2}$ 의 힘까지 견디며, 탄성한계는 70 $80 \mathrm{daN} / \mathrm{mm}^{2}$, 파열점은 $110 \mathrm{daN} / \mathrm{mm}^{2}$ 로 알려겨 있 다라. 유도나사는 각도와 countersinking만 적 절히 맞추어 주면 어느 정도 강성고정이 가능 하고, 조작이 쉽고 과두부에서도 구강내 관혈 적 정복술이 가능한 장점이 있다. 이 유도나사 ${ }^{8)}$ 는 일반적인 나사와 다른 모양을 갖는데, 유 
도나사는 그 끝에만 나사선을 갖고 있어서, 가 까운 쪽 피질에는 나사머리가 작용되며, 먼 쪽 피질에는 나사선이 작용하여, 이룰 조임으로써 압박에 의한 어느 정도의 강성고정이 가능하 다. 과거 강선 고정의 경우 4 내지 6주정도의 악간고정이 필수적이었으나 $\mathrm{DCP}$, miniplate, 유도나사의 경우 악간고정을 생략하거나 짭게 또는 tension band로서 arch bar만 사용할 수 있다. 저자들의 경우에서도 miniplate를 사용한 14 례중 2 례에서는 악간고정을 하지 않았으며 나머지 12 례에서도 평균 2 주이내의 악간고정 을 시행하였다. 또한 seizure disorder, poor nutrition, respiratory disease가 있는 경우 악 간고정이 금기로 되어 있으며, Glineburg 등은 8 주간 악간고정을 하여 고정 후 악관절 관절 연골의 현저한 변화가 관찰되며, 8 개월 후에도 기능의 완전 회복이 보이지 않는다고 하였다 ${ }^{16)}$.

무치 환자의 하악 골절 치료에 있어서 Marciani와 $\mathrm{Hill}^{13)}$ 은 53 명의 무치 하악 골절의 치 료를 분석하여, 영향을 미치는 주요 인자로서 골절부위, 치조골의 높이, 환자의 전신 상태에 의해 치료방법이 결정된다고 하였으며, Bruce 와 Strachen ${ }^{6)}$ 은 위축성 무치 하악골절 146 례를 여러 방법으로 치료한 결과, 약 $20 \%$ 에서 불유 합이 발생하였다고 하였다. 무치 상태에서는

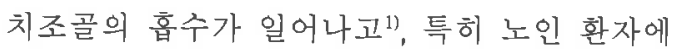
서는 하치조동맥이 제 기능을 못하므로 대부분 골막 혈관총이 하악의 주된 혈류 공급원이 되 는데 ${ }^{4)}$, 관혈적 정복시 골막을 박리하면 혈류 공급에 지장을 주어 불유합을 초래하는 원인이 될 수 있다. 따라서 체부의 높이가 $20 \mathrm{~mm}$ 가 안 되는 경우에는 비관혈적 방법으로 치료하여야 한다고 하였다 ${ }^{13}$. 또한 치아가 있는 경우 충격 을 홉수하여 방어 작용을 할 수 있는데 그렇치 못한 무치 하악의 경우 충격이 그대로 하악의 다른 부위에 전달되는데, 이때 특히 과두부가 손상 받기 쉽다고 하였담. 보존적 치료 방법 으로는 환자의 의치롤 이용하거나 아크릴 부목 등을 이용할 수 있고, miniplate로써 악간고정 을 대신하는 방법도 있겠다마. 무치 하악의 경 우도 체부의 높이가 $20 \mathrm{~mm}$ 를 넘으면서 전위가 있으면, 구강내 관혈적 정복술이 가능한데, 저
자들외 경우 60 세 이상에서 무치 하악골절이 좌측 체부와 우측 과두경부에 발생한 경우가 1 례 있었으며, 체부는 구강내 접근법으로 miniplate 2 개를 사용하여 고정하였으며, 과두경 부는 parotidectomy incision을 통하여 체외 접 근으로 miniplate 2 개를 사용하여 고정하였고, arch bar와 악간고정은 시행치 않았다. 이 환 자의 경우 8 개월 이상 추적 검사하였으나 별 다른 합병증 없이 좋은 결과를 얻을 수 있었다.

\section{결 론}

저자들은 최근 구강내 접근법을 이용하여 하악 골절의 치료를 경험하였으며 만족할 만한 결과를 얻었기에 문헌고찰과 함께 보고하는 바이다.

\section{References}

1. Amaratunga NA: A comparative study of the clinical aspect of edentulous and dentulous mandibular fractures. J Oral Maxillofac Surg 46:3 5, 1988

2. Amaratunga NA: The effect of teeth in the line of mandibular fractures on healing. J Oral Maxillofac Surg 45:312 314, 1987

3. Bochlogyros PN: A retrospective study of 1,521 mandibular fractures. J Oral Maxillofac Surg 43: 597 599, 1985

4. Bradley JC: A radiological investigation into the age changes of the inferior dental artery. Br J Oral Surg 13(1) : 82 90, 1975

5. Bruce $\mathrm{R}$ and Fonseca RJ : Mandible fractures, In Oral and Maxillofacial Trauma (ed. Fonseca RJ and Walker RV), Philadelphia, Saunders, pp359 417, 1991

6. Bruce RA and Strachen DS: Fractures of the edentulous mandible: Chalmer J. 
Lyon Academy study. J Oral Surg 34(11)

: 937 979, 1976

7. Dierks EJ : Transoral approach to fractures of the mandible. Laryngoscope 97 : 4 6, 1987

8. Ellis Ill $\mathrm{E}$ and Ghali GE : Lag screw fixation of anterior mandibular fractures. J Oral Maxillofac surg 49:13 21, 1991

9. Ellis III E, Moos $\mathrm{KF}$ and El-Attar $\mathrm{A}$ : Ten years of mandibular fractures: An analysis of 2,137 cases. Oral Surg 59(2) : $120 \sim 129,1985$

10. James RB, Fredrickson C and Kent JN : Prospective study of mandibular fractures. J Oral Surg $39: 275 \sim 281,1981$

11. Kellman RM : Methods of rigid fixation for facial fractures, In OtolaryngologyHead and Neck Surgery(ed. Cummings CW et al) Update I, St. Louis, Mosby, pp 166 191, 1989

12. Levy FE, Smith RW, Odland RM et al :
Monocortical miniplate fixation of mandibular angle fractures. Arch Otolaryngol Head Neck Surg $117: 149 \sim 154,1991$

13. Marciani RD and Hill OJ : Treatment of the fractured edentulous mandible. J Oral Surg $37: 569 \sim 577,1979$

14. Oikarinen $\mathrm{K}$, Altonen $\mathrm{M}$, Kauppi $\mathrm{H}$ et al : Treatment of mandibular fractures.

J Cranio-Max-Fac Surg 17:24 30, 1989

15. Shetty $V$ and Freymiller $E:$ Teeth in the line of fracture: A review. J Oral Maxillofac Surg $47: 1303 \sim 1306,1989$

16. Wald RM, Abemayor E, Zemplenyi $J$ et al: The transoral treatment of mandibular fractures using noncompression miniplates: A prospective study. Ann Plast Surg 20(5) : 409 413, 1988

17. Wolfe SA, Lovaas M, McCafferty LR : Use of a miniplate to provide inter-maxillary fixation in the edentulous patient. J Cranio-Max-Fac Surg $17: 31 \sim 33,1989$ 